\title{
AN AUDIT OF ECTOPIC PREGNANCY IN A TERTIARY CARE HOSPITAL
}

\author{
${ }^{1}$ Sunita Samal, ${ }^{2} \mathrm{P}$ Pallavee, ${ }^{3}$ Seetesh Ghose \& ${ }^{4}$ Anita A \\ Mahatma Gandhi Medical College \& Research Institute, Pilliyarkuppam, Puducherry, 607402, India
}

\begin{abstract}
*Corresponding Author Email: sunisamal@rediffmail.com
ABSTRACT

Introduction: Ectopic pregnancy is of greater importance in modern obstetrics because of its increasing incidence and impact on female fertility. The present study involves retrospective analysis of ectopic pregnancies admitted to MGMC \& RI from January 2011 to December 2012. Objective: To analyse demographic variables, the risk factors, clinical presentation and outcome and management of ectopic pregnancy. Materials \& Methods: A total of 54 ectopic pregnancies who were admitted to MGMC \& RI from January 2011 to December 2012 were studied with respect to history, clinical presentation, investigations, management. Result: The frequency of ectopic pregnancy was $1.2 \%$. Multiparous women were more prone to had ectopic (79.6\%). Majority of them had risk factors (75.9\%) of which history of abortion (24\%) was the leading cause. The commonest symptom was pain with bleeding $p / v$ (37\%) and only 6 patients were presented with shock. Clinical evaluation, ultrasound, urine pregnancy test were the investigation tools. The gestational age ranged between 4-13 wks and most frequent was 7-10wk (46\%). All the cases were managed surgically. On laparotomy most were ampullary rupture. The main treatment modality was partial salpingectomy. We had one mortality due to late referral to our hospital. Conclusion: Early diagnosis and timely intervention can reduce maternal morbidity and mortality. Though the recent trend in management is conservative surgical or medical approach, radical surgery was the main treatment modality in present study mostly due to late referral of the patients.
\end{abstract}

\section{KEY WORDS}

Abortion, Ampulla, Ectopic pregnancy, Laparotomy, Salpingectomy

\section{INTRODUCTION:}

An ectopic or extrauterine pregnancy is one in which the blastocyst implants anywhere other than the endometrial lining of the uterine cavity. Ectopic pregnancy is a common life threatening emergency in pregnancy and the leading cause of maternal deaths in the first trimester. It is an important cause of maternal morbidity and mortality especially in developing countries where majority of the patients tend to present late with ruptured form and compromised hemodynamic status. The incidence of ectopic pregnancy varies from country to country and within the same geographical region depending on the risk factors in the population concerned. It has become a global problem and has shown a rising incidence during the last 3 decades all over the world ${ }^{1,8}$. This increase is especially due to increase in pelvic infections, advances in assisted reproductive technology, tubal surgeries and sterilizations, use of intrauterine devices and earlier diagnosis with more sensitive tools of cases that otherwise would have resolved without any symptom $^{1,8}$. Moreover, the availability of sensitive BhCG assay and high- resolution transvaginal sonography has resulted in earlier diagnosis and thus reduced mortality rate due to early intervention ${ }^{6}$. The treatment is influenced by the clinical state of the patient, the site of the ectopic gestation, the fertility status of the patient and the available facilities and technology. Surgical treatment for ectopic is still the norm and 'gold standard' ${ }^{12}$ and may be laparotomy or laparoscopy. The surgical procedure may also be radical (salpingectomy) or conservative (linear salpingotomy) ${ }^{12}$. This study therefore reviewed patients with ectopic gestations in our centre with the aim of ascertaining the 
epidemiological, diagnostic and therapeutic modalities currently employed. It will also compare with trends elsewhere and advocate improvement in diagnosis and management.

\section{MATERIALS AND METHODS:}

This was a retrospective analysis of 54 patients admitted with ectopic pregnancy at Mahatma Gandhi Medical College \& Research Institute from January 2011 to December 2012. The case notes of the patients with ectopic pregnancy were traced through medical record department. The labour ward register was used to ascertain the total number of admission of pregnant women for the same period. Information on the sociodemographic data, clinical symptoms and signs, diagnostic tools employed; sites and treatment options, risk factors for the disease as well as associated morbidity and mortality were noted. The data was analysed with simple descriptive statistics and presented in frequency charts and tables.

\section{RESULT:}

In the 2-year review period, there were a total of 4488 pregnant patients admitted to labour ward and 54 ectopic gestations were recorded. This gives an incidence of $1.2 \%$ of total pregnancies. The majority $32(59.2 \%)$ were in the age group 20 - 30 years. Multigravida women accounted for $79.6 \%$ of all cases, while primigravidas were only $20.3 \%$. (Table 1 ). The most common risk factors in the study were: previous abortions $13(24.07 \%)$, sterilization surgeries and infertility each $8(14.8 \%)$ and recanalization surgeries $6(11 \%)$, while PID were only $4(7.41 \%)$ and $13(24.07 \%)$ patients didn't have any risk factors. (Table 2). All the patients had tubal ectopic pregnancies at the time of presentation. Thirty-six (66.6\%) were ampullary, $10(18.5 \%)$ isthmic, $7(12.9 \%)$ fimbrial while only $1(1.8 \%)$ of the patients had interstitial ectopic. In $64.8 \%$ of the patients, the ectopic pregnancy was on the right while the remaining $35.1 \%$ had on left side. While $28(51.85 \%)$ presented with ruptured condition, only 5(9.25\%) patients were presented as unruptured and $21(38.88 \%)$ had tubal abortion.(Table 3) Abdominal pain and bleeding was the leading clinical presentation $20(37.04 \%)$ followed by only lower abdominal pain in $18(33.3 \%)$ cases and $6(11.11 \%)$ patients presented with haemorrhagic shock, while $10(18.5 \%)$ were totally asymptomatic.(Table 4) All the patients were presented with history of amenorrhoea, among them 25(46.3\%) had 7-10wk, 23(42.5\%) 4-7wk and only 6(11.11\%) had 10-13wks of amenorrhoea.(Table 5) Almost all had urinary pregnancy positive $51(94.4 \%)$ but $2(3.7 \%)$ had negative test though both had ruptured ectopic. All the patients were managed surgically and 51(94.4\%) through laparotomy, while $3(5.5 \%)$ by laparoscopy(Table-6). The most common intraoperative procedure was partial salpingectomy $49(90.7 \%), 1(1.8 \%)$ had undergone total salpingectomy for interstitial pregnancy, salpigostomy was done in $1(1.8 \%)$ case and $3(5.5 \%)$ were treated by milking of tube. (Table 6) Intra-operatively maximum 29(53.7\%) had haemoperitoneum of less than $500 \mathrm{ml}$, where as15(27.7\%) had $500-1500 \mathrm{ml}$ and 7 had 1500 $3500 \mathrm{ml}($ Table-7). Only 10(18.5\%) patients needed blood transfusions intra or post-operatively. We had only on mortality due to late referral of the patient to us.

Table-1

\begin{tabular}{|l|l|l|}
\hline Demographic variables & Frequency & Percentage \\
\hline Age & & \\
\hline$<20$ & 1 & $1.85 \%$ \\
\hline $20-30$ & 32 & $59.26 \%$ \\
\hline$>30$ & 21 & $38.89 \%$ \\
\hline Parity & & \\
\hline Primi & 11 & $20.37 \%$ \\
\hline Multi & 43 & $79.63 \%$ \\
\hline Total (N) & $\mathbf{5 4}$ & $\mathbf{1 0 0 \%}$ \\
\hline
\end{tabular}


Table-2

\begin{tabular}{|l|l|l|}
\hline Risk factors & Freq & Percentage \\
\hline Abortion & 13 & $24.07 \%$ \\
\hline Sterilisation & 8 & $14.81 \%$ \\
\hline Infertility & 8 & $14.81 \%$ \\
\hline Previous ectopic & 2 & $3.70 \%$ \\
\hline Recanalisation & 6 & $11.11 \%$ \\
\hline PID & 4 & $7.41 \%$ \\
\hline No risk factors & 13 & $\mathbf{2 4 . 0 7 \%}$ \\
\hline Total & $\mathbf{5 4}$ & $\mathbf{1 0 0 \%}$ \\
\hline
\end{tabular}

Table-3

\begin{tabular}{|l|l|l|}
\hline Site of Ectopic & Freq & Percentage \\
\hline Ampulla & 36 & $66.6 \%$ \\
\hline Isthmic & 10 & $18.5 \%$ \\
\hline Interstitial rupture & 1 & $1.85 \%$ \\
\hline Fimbrial abortion & 7 & $12.9 \%$ \\
\hline Type of Presentation & & \\
\hline Ruptured & 28 & $51.85 \%$ \\
\hline Abortion & 21 & $38.88 \%$ \\
\hline Unruptured & 5 & $9.25 \%$ \\
\hline Side & & \\
\hline Right & 35 & $64.81 \%$ \\
\hline Left & 19 & $35.19 \%$ \\
\hline Total & $\mathbf{5 4}$ & $\mathbf{1 0 0 \%}$ \\
\hline
\end{tabular}

Table-4

\begin{tabular}{|l|l|l|}
\hline Presentation & Freq & Percentage \\
\hline Shock & 6 & $11.11 \%$ \\
\hline Pain \& bleeding & 20 & $37.04 \%$ \\
\hline Pain & 18 & $33.33 \%$ \\
\hline Asymptomatic & 10 & $18.52 \%$ \\
\hline Total & $\mathbf{5 4}$ & $\mathbf{1 0 0 \%}$ \\
\hline
\end{tabular}

Table-5

\begin{tabular}{|l|l|l|}
\hline Amenorrhoea & Freq & Percentage \\
\hline 4-7wk & 23 & $42.59 \%$ \\
\hline 7-10wk & 25 & $46.30 \%$ \\
\hline $10-13 w k$ & 6 & $11.11 \%$ \\
\hline Total & $\mathbf{5 4}$ & $\mathbf{1 0 0 \%}$ \\
\hline
\end{tabular}


Table-6

\begin{tabular}{|l|l|l|}
\hline Mode of Treatment & Freq & Percentage \\
\hline Salpingostomy & 1 & $1.85 \%$ \\
\hline Total salpingectomy & 1 & $1.85 \%$ \\
\hline Milking & 3 & $5.56 \%$ \\
\hline Partial salpingectomy & 49 & $90.74 \%$ \\
\hline Route of entry & & \\
\hline Laparotomy & 51 & $94.44 \%$ \\
\hline Laparoscopic & 3 & $5.56 \%$ \\
\hline Total & $\mathbf{5 4}$ & $\mathbf{1 0 0 \%}$ \\
\hline
\end{tabular}

Table-7

\begin{tabular}{|l|l|l|}
\hline Haemoperitoneum & Freq & Percentage \\
\hline$<500 \mathrm{ml}$ & 29 & $53.70 \%$ \\
\hline $500-1.5$ litre & 15 & $27.78 \%$ \\
\hline $1.5-3.5$ litre & 7 & $12.96 \%$ \\
\hline No haemoperitoneum & 3 & $5.56 \%$ \\
\hline Total & $\mathbf{5 4}$ & $\mathbf{1 0 0} \%$ \\
\hline
\end{tabular}

\section{DISCUSSION:}

The incidence of ectopic pregnancy has been rising during the last few decades throughout the world. The incidence of $1.2 \%$ in present study was comparable to similar studies by Udigwe et al $(1.31 \%)^{11}$, Gaddagi et al (1:399pregnancies) $)^{2}$, but Arup Kumar et al showed low incidence of $0.6 \%{ }^{1}$. The peak age was $20-30$ years (59.2\%) (Table 1) which was consistent with the findings by Arup Kumar et $\mathrm{al}^{1}$, Igbarese et $\mathrm{al}^{5}$ and Gaddagi et $\mathrm{al}^{2}$. Thus, women in reproductive age groups are more prone for ectopic. The predominant risk factor being previous abortions (24.07\%) followed by tubal surgeries (sterilisation-14.8\%, recannalisation-11.1\%) (Table 2) were suggestive of tubal damage as a final common pathway which was consistent with the findings in Rose Jophy et al (abortions - $25.8 \%$ ). Infertility accounts for $14.8 \%$ and half of the patient among them were on ovulation induction. Agents that induce ovulation may increase the risk of ectopic gestation, through the effects of hormone fluctuation on tubal function. History of pelvic inflammatory disease was only $7.1 \%$ in our study, though it was a strong etiological factor in other studies. It is also important to note that there was no history of use of hormonal contraceptives and IUCD, though Arup Kumar et al found an association of $6.1 \%{ }^{1}$. The ICMR study that showed no association may well be true 4 . Surprisingly no risk factor was identified in $24.07 \%$ of cases. In the present study $3.7 \%$ had previous history of ectopic pregnancy which was comparable to Rose et al study (.3.2 \%) but little higher than study by Gaddagi et al (2.7\%). This is because tubal disease is nearly always bilateral and there is a strong tendency for ectopic pregnancy to occur first on one side and then later on the other side. The symptoms at presentation: abdominal pain, amenorrhea, syncopal attack and vaginal bleeding followed the global trend ${ }^{1}$, Patients with an ectopic pregnancy commonly present with pain and vaginal bleeding between 6 and 10 weeks' gestation ${ }^{13}$ Majority of our patients were presented with pain and vaginal bleeding(37.04\%) between 7 and 10 wks of amenorrhoea(46.3\%) followed by only pain in 33.3\%(Table 4).More recently, it has been reported that one third of women with ectopic pregnancy have no clinical signs and $9 \%$ have no symptoms. ${ }^{12}$. We found a $18.52 \%$ of cases without any signs and symptoms though few of them had rupture at the time of presentation. All the patients were subjected to transvaginal sonography for confirmation of diagnosis along with urine pregnancy test. A ruptured ectopic pregnancy should be strongly suspected if a woman has a positive pregnancy test and presents with syncope and signs of shock including tachycardia, pallor and collapse. In contrary to this in present study two 
patients who had rupture ectopic had negative pregnancy test. We had $51.8 \%$ cases with ruptured ectopic which was in contrary to findings from other developing countries where 70 to $95 \%$ of cases were ruptured at presentation ${ }^{5,8}$. But tubal abortion was a significant finding leading to haemoperitoneum in $38.8 \%$ cases and three patient presented as unruptured ectopic. Most of the patients had ampullary ectopic pregnancy $(66.6 \%)$ which was consistent with studies from other centres. ${ }^{10}$ The preponderance of ectopic pregnancies on the right $(64.8 \%)$ was similar to the trend all over the world. ${ }^{3,6}$ This right sided preponderance has been attributed to appendicitis. Although surgery is the mainstay of management, expectant and medical therapy can be offered to prevent fertility impairement ${ }^{1}$. However, in our study as in many developing countries, salpingectomy (90.74\%) was done due to late presentation and also most of them were multigravida. Milking was done only in $3.55 \%$ cases as they had fimbrial abortions and there was no active bleeding. One infertility patient had undergone salpingostomy as contralateral salpingectomy had already been done due to previous ectopic. None of the patients were advocated medical management in our study because of non-acceptance by the patients and also due to late presentations. In the developed world, minimal access (laparoscopic) surgery has become the preferred technique unless the woman is haemodynamically unstable. Though most of our patients were haemodynamically stable, laparoscopy was performed only in three cases as most of the surgeries were done in emergency hours and also due to lack of laparoscopic skill among the junior consultants. We had one mortality in our small series as the patient was referred to us at a stage of irreversible shock due to massive haemoperitoneum. Other study had mortality rate of $1.5 \%^{5}$

\section{CONCLUSION:}

Ectopic pregnancy still remains a major gynaecological problem associated with notable mortality and morbidity. A high prevalence of unsafe abortions result in high incidence of ectopic pregnancy. Poverty, ignorance, late presentation, nonavailability of modern diagnostic tools are the problems of early detection and prompt treatment of ectopic pregnancy in developing nations. Though conservative surgical or medical treatment is the recent trend in the management of ectopic pregnancy, radical surgery or salpingectomy was the major treatment modality in the present study. Emphasis should be on prevention and early detection so as to give patients opportunities for tubal conserving treatment.

\section{REFERENCE:}

1. $\quad$ Arup K. M., Niloptal R., Kakali S. K., Pradip K. B. 2007. Ectopic Pregnancy an analysis of 180 cases. Journal of the Indian MedAssoc ;105: 308-14.

2. Rajkhowa M., Glass M. R., Rutherford A. J., Balen A. H. et al. 2000. Trends in the incidence of ectopic pregnancy in England and Wales from 1966-1996. BJOG ; 107(3): 36974.

3. Ory SJ, Villaneva AL, Sand PK. et al. 1986. Conservative treatment of ectopic pregnancy with methotrexate. Am. J. Obstet. Gynecol; 154:1299-306.

4. Walker J.J. Ectopic pregnancy. In: Clinical Obstetrics and Gynaecology. Lippincott William \& Wilkins, Inc 2007; 50(1): 89-99.

5. Udigwe G O, Umeononihu O S, Mbachu I I. 2010. Ectopic Pregnancy: A 5yr review of cases at Nnamdi Azikiwe University Teaching Hospital (NAUTH) Nnewi. Niger Med J;51:160-3

6. Gaddagi A ChandrashekharA P. 2012. A Clinical Study Of Ectopic Pregnancy. Journal of Clinical and Diagnostic Research;6(5): 867-869

7. Igbarese G. O., Ebeigbe P. N., Igbekoyi O. F., Ajufoh B. I. 2005. Ectopic Pregnancy an 11-year review in a tertiary centre in the Niger Delta. Trop Doct ; 35: 175-7

1. ICMR: ICMR Task Force Project.1990. multicentre case control study of ectopic pregnancy in India. J Obstet Gynaecol India : 40: 425-30.

8. Walker JJ. 2007. Ectopic pregnancy. Clin Obstet Gynecol ;50:89-99

9. Poonam Y., Uprety D., Banerjee B. 2005. Ectopic Pregnancy - two years review from BPKIHS, Nepal. Kathmandu University Med J; 3:365-9.

10. Swende T. Z., Jogo A.A. 2008. Ruptured tubal pregnancy in Makurdi, North Central Nigeria. Niger J Med ; 17(1): 75-7.

11. Gharoro E. P., Igbafe A. A. 2002. Ectopic Pregnancy revisited in Benin City: analysis of 152 cases. Acta Obstet Gynaecol Scand ; 81(12):1139-43.

12. Musa J., Daru P. H., Mutihir J. T., Ujah I. A. 2009. Ectopic pregnancy in Jos Northern Nigeria-prevalence and impact on subsequent fertility.Niger J Med ; 18(1): 35-8. 
13. Vanitha N Sivalingam, W Colin Duncan, Emma Kirk, et al. 2011. Diagnosis and management of ectopic pregnancy.J Fam Plann Reprod Health Care.; 37(4): 231-240. 